\title{
PENGARUH UKURAN MATA PANCING RAWAI DASAR TERHADAP HASIL TANGKAPAN
}

\author{
Wudianto ${ }^{*}$, Mahiswara ${ }^{*)}$ dan Martin Linting ${ }^{*}$
}

\begin{abstract}
ABSTRAK
Beberapa jenis ikan demersal mempunyai nilai ekonomis penting seperti kakap dan kerapu. Rawai dasar sampai saat ini dianggap sebagai alat tangkap yang paling efektif digunakan untuk menangkap ikan demersal. Penelitian tentang pengaruh ukuran mata pancing rawai dasar terhadap hasil tangkapan telah dilakukan di perairan sebelah Timur Bali mulai bulan Mei 1994 sampai dengan Januari 1995. Dengan menggunakan 3 macam ukuran mata pancing yaitu No. 5, 6 dan 7 yang dioperasikan secara bersamaan ternyata hasil tangkapan yang diperoleh tidak berbeda nyata, namun terdapat kecenderungan mata pancing yang berukuran kecil (No. 5 dan 6) lebih efektif dibanding mata pancing yang lebih besar (No. 7). Hasil tangkapan tinggi diperoleh rawai dasar yang dioperasikan di perairan yang agak dalam $(>50 \mathrm{~m}$ ) seperti perairan Tukadabu. Jenis ikan ekonomis penting yang banyak tertangkap selama pengoperasian rawai dasar adalah kakap (Lutjanus spp.), kerapu (Epinephelus spp.) dan kue (Caranx spp.). Ukuran ikan yang tertangkap tidak dipengaruhi oleh ukuran mata pancing yang digunakan.
\end{abstract}

\section{ABSTRACT: Influence of Hook Sizes of Bottom Longline on Catch, by: Wudianto, Mabiswara and Martin Linting}

Some demersal species such as snapper and grouper are economically important species. Bottom long line is efectively used for catching those species. Research on the influence of hook sizes for bottom long line have been conducted in eastern part of Bali during May 1994 to January 1995. Three hook sizes i.e. Nos. 5, 6 and 7 were tested. The result indicated that in this study there were no significant different by the catch among the sizes of the hooks, however, there is an indication that the small sizes hooks (Nos. 5 and 6) performed better catch rate than the big one. The high catch rate of bottom long line was recorded in the deeps fishing ground such as Tukadabu waters. The economically important spesies of fish caught by experimental bottom longline were dominated by snapper (Lutjanus spp.), grouper (Epinephelus spp.) and jackfish (Caranx spp.). The size of fish were not effected by hook sizes.

KEYWORDS: Bottom longline, book size, catch

\section{PENDAHULUAN}

Ikan demersal merupakan kelompok ikan yang hidup di dasar perairan terutama di landas benua. Berdasarkan tipe ekologi perairan yang didiaminya, Longhurst dan Pauly (1987) menggolongkan ikan demersal ke dalam 3 kelompok yaitu kelompok yang senang hidup di dasar lumpur, kelompok yang hidup di dasar pasir, dan kelompok yang hidup di dasar karang. Jenis ikan kakap, lencam dan kerapu yang termasuk ke dalam famili Lutjanidae, Lethrinidae, dan Serranidae lebih senang hidup di perairan berdasar karang.

Beberapa jenis ikan demersal mempunyai nilai ekonomis penting, untuk konsumsi domestik atau untuk ekspor. Jenis ikan kakap dan kerapu termasuk jenis komoditi ekspor yang dapat diandalkan. Ikan kakap diekspor dalam 
bentuk beku atau filet segar, sedang ikan kerapu diekspor dalam bentuk beku atau hidup. Selama periode waktu antara tahun 1986-1991, rata-rata kenaikan produksi tahunan ikan kakap dan kerapu masing-masing adalah 12,6\% dan 11,4\% (Ditjenkan, 1993).

Usaha penangkapan ikan kakap dan kerapu umumnya masih dilakukan oleh nelayan skala kecil dan masih sedikit mendapat perhatian dari usaha perikanan skala menengah dan industri. Penangkapan ikan kakap dan kerapu yang senang hidup di perairan berdasar karang dilakukan dengan berbagai jenis alat tangkap seperti jaring insang dasar, bubu, pancing ulur, rawai dasar dan sebagainya. Namun sampai saat ini yang dianggap cukup efektif untuk menangkap ikan tersebut di atas adalah rawai dasar sehingga alat tangkap ini banyak dioperasikan oleh nelayan. Rawai dasar yang dioperasikan oleh nelayan umumnya menggunakan ukuran mata pancing yang bervariasi dari ukuran kecil sampai besar (No. 4-9). Dengan mata pancing yang berbagai ukuran ini, belum diketahui ukuran mata pancing yang mana yang mempunyai efektivitas tinggi dalam mendapatkan hasil tangkapan (tanpa merusak kelestarian sumber daya ikan yang ditangkap). Koike dan Takeuchi (1970) menyatakan bahwa tingkat efesiensi penangkapan dengan alat tangkap pancing untuk jenis dan ukuran ikan tertentu ditentukan oleh besarnya ukuran mata pancing yang digunakan.

Berdasarkan hal tersebut di atas maka penelitian mengenai pengaruh ukuran mata pancing rawai dasar terhadap hasil tangkapan sangat diperlukan. Hasil penelitian ini diharapkan dapat digunakan sebagai bahan untuk pengembangan usaha perikanan demersal terutama yang selama ini melakukan penangkapan ikan kakap dan kerapu dengan alat tangkap rawai dasar.

\section{BAHAN DAN METODE}

Rawai dasar yang diujicobakan terdiri dari tali utama PE diameter $5 \mathrm{~mm}$, tali cabang PA monofilament No.1000 sepanjang $30 \mathrm{~cm}$, kili-kili dan kawat monel sepanjang $20 \mathrm{~cm}$ serta mata pancing (Gambar 1). Tali cabang dipasang pada tali utama dengan jarak $4 \mathrm{~m}$. Sedang mata pancing yang digunakan terbuat dari baja dengan 3 macam ukuran mata pancing yakni mata pancing No.5, 6 dan 7. Adapun spesifikasi dari masing-masing ukuran mata pancing yang digunakan seperti pada Tabel 1.

Untuk mengoperasikan rawai dasar digunakan perahu kayu berukuran panjang 8,2 m, lebar $1,6 \mathrm{~m}$, dan dalam 0,5 $\mathrm{m}$ dengan dilengkapi mesin dalam berkekuatan 10,5 HP. Jumlah tenaga yang diperlukan untuk mengoperasikan rawai dasar sebanyak 4-5 orang. Sebagai bahan penarik ikan sasaran agar mau memakan pancing digunakan umpan berupa ikan segar. Beberapa jenis ikan umpan yang digunakan adalah ikan lemuru, kembung dan tongkol. Bagi ikan yang berukuran kecil seperti lemuru digunakan masih dalam keadaan utuh sedang ikan umpan yang besar dipotong menjadi ukuran antara 50-100 gram. 
Ketiga ukuran mata pancing mendapat perlakuan yang sama terhadap jenis dan ukuran umpan yang digunakan.

Tabel 1. Spesifikasi mata pancing rawai dasar

Table 1. Spesification of books for bottom longline

\begin{tabular}{llccc}
\hline \multirow{2}{*}{$\begin{array}{c}\text { Specification } \\
\text { S }\end{array}$} & & \multicolumn{3}{c}{ Mata pancing / Hooks } \\
\cline { 3 - 5 } & & No. 5 & No.6 & No. 7 \\
\hline Tinggi (Lengtb) & $\mathrm{cm}$ & 5,2 & 5,8 & 6,3 \\
Lebar (Width) & $\mathrm{cm}$ & 2,0 & 2,2 & 2,5 \\
Pengait (Barb) & $\mathrm{cm}$ & 0,9 & 1,0 & 1,1 \\
\hline \hline
\end{tabular}

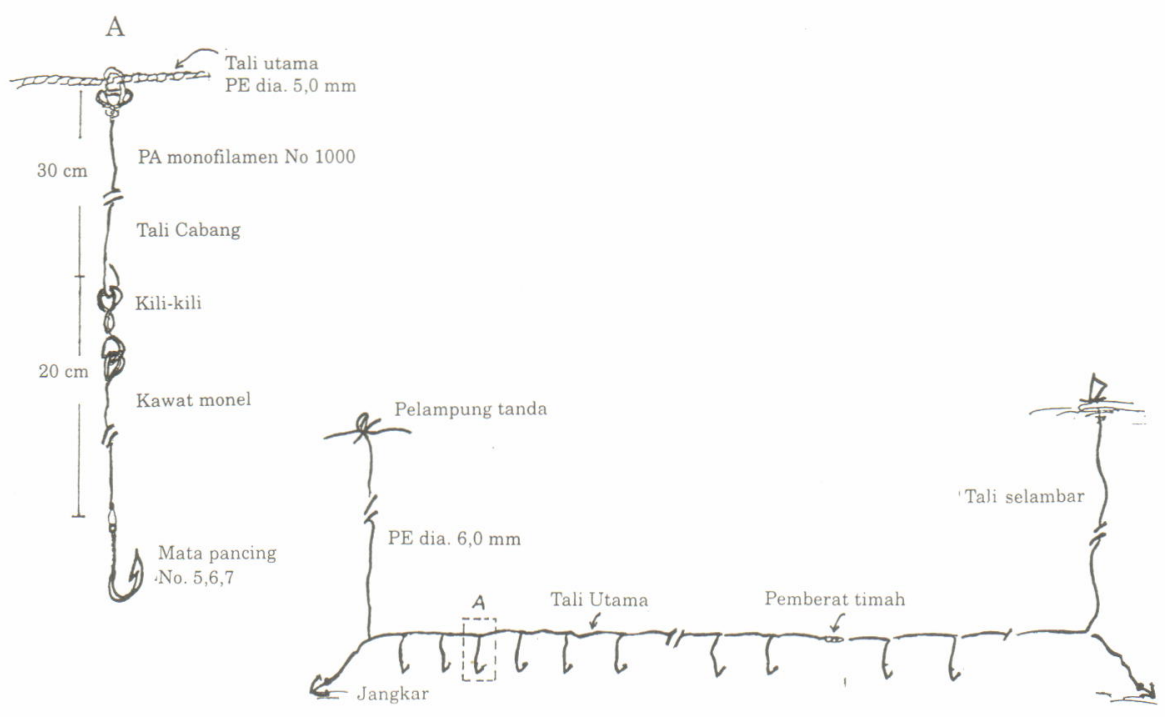

Gambar 1. Rancang bangun rawai dasar

Figure 1. Design of bottom longline 
Rawai dasar dioperasikan di perairan karang sebelah timur Bali, tepatnya di dua lokasi yaitu Jemeluk dan Tukadabu pada bulan Mei 1994 sampai dengan Januari 1995. Rawai dasar dioperasikan pada kedalaman antara 20-150 m pada waktu malam hari. Lama pancing di dalam air berkisar antara 3-4 jam. Selama uji coba penangkapan dilakukan pada 46 stasiun penangkapan dengan rincian 34 stasiun panangkapan di perairan Jemeluk dan 12 stasiun penangkapan di perairan Tukadabu. Ketiga ukuran mata pancing dirangkai menjadi satu dengan posisi selang-seling dan dioperasikan secara bersamaan. Jumlah mata pancing yang dioperasikan tidak selalu sama untuk setiap stasiun penangkapan berkisar antara 40-80 buah untuk masing-masing ukuran mata pancing. Hal ini disebabkan terdapat sebagian mata pancing yang rusak sehingga perlu adanya perbaikan. Untuk mengetahui kemampuan rawai dasar dalam menangkap ikan digunakan "hook rate" (laju pancing) yaitu banyaknya ikan yang tertangkap oleh 100 mata pancing yang digunakan. Hasil tangkapan yang diperoleh dari pengoperasian rawai dasar setiap stasiun penangkapan, diidentifikasi jenisnya kemudian dipisahkan berdasarkan jenis ikan untuk masing-masing ukuran mata pancing yang digunakan. Ikan yang tertangkap kemudian diukur berat maupun panjangnya. Untuk mengetahui produktivitas masing-masing ukuran mata pancing, dilakukan uji komparatif rata-rata dengan ANOVA terhadap laju tangkapnya (Sudjana, 1984). Jenis ikan yang dominan tertangkap dan mempunyai nilai ekonomis penting diukur panjang totalnya kemudian dikelompokkan berdasarkan ukuran mata pancing untuk mengetahui adanya hubungan antara ukuran mata pancing dan besar ikan yang tertangkap.

\section{HASIL DAN PEMBAHASAN}

Hasil tangkapan rawai dasar pada masing-masing stasiun penangkapan yang dinyatakan dalam book rate (laju pancing) berdasarkan ukuran mata pancing di perairan Jemeluk disajikan pada Tabel 2 dan untuk perairan Tukadabu disajikan pada Tabel 3. Dari Tabel 2 terlihat bahwa rata-rata laju pancing rawai dasar yang dioperasikan di perairan Jemeluk untuk setiap ukuran mata pancing adalah mata pancing No.5 sebesar 1,38, mata pancing No.6 sebesar 1,23, dan mata pancing No.7 sebesar 1,08.

Rata-rata laju pancing rawai dasar yang dioperasikan di perairan Tukadabu (Tabel 3) lebih tinggi untuk semua ukuran mata pancing dibanding dengan rawai dasar yang dioperasikan di perairan Jemeluk. Dari hasil pengamatan menunjukkan bahwa rata-rata laju pancing untuk mata pancing No.5 sebesar 2,65, mata pancing No.6 sebesar 5,28, dan mata pancing No.7 sebesar 2,08. Tingginya hasil tangkapan kemungkinan disebabkan oleh perbedaan kedalaman perairan daerah penangkapan di mana di Jemeluk, rawai dasar dioperasikan di perairan dengan kedalaman antara $20-50 \mathrm{~m}$, sedang di perairan Tukadabu pada kedalaman lebih dari $50 \mathrm{~m}$. Di perairan yang agak dalam ini banyak dihuni jenis ikan yang menjadi tujuan penangkapan seperti kakap, kerapu dan cucut. 
Tabel 2. Laju pancing (book rate) dari rawai dasar berdasarkan ukuran mata pancing di perairan Jemeluk, Timur Bali

Table 2. Hook rate of bottom long line based on book sizes operated in Jemeluk waters, eastern part of Bali

\begin{tabular}{|c|c|c|c|}
\hline \multirow{2}{*}{$\begin{array}{l}\text { No. Stasiun } \\
\text { No. Station }\end{array}$} & \multicolumn{3}{|c|}{ Laju pancing / Hook rate } \\
\hline & $\begin{array}{l}\text { Mata pancing } \\
\text { (Hook) No.5 }\end{array}$ & $\begin{array}{l}\text { Mata pancing } \\
(\text { Hook) No.6 }\end{array}$ & $\begin{array}{l}\text { Mata pancing } \\
(\text { Hook }) \text { No.T }\end{array}$ \\
\hline 01 & 1,33 & 0,00 & 2,67 \\
\hline 02 & 0,00 & 1,33 & 0,00 \\
\hline 03 & 2,67 & 0,00 & 1,33 \\
\hline 04 & 1,33 & 1,33 & 1,33 \\
\hline 05 & 1,33 & 2,67 & 0,00 \\
\hline 06 & 1,33 & 0,00 & 1,33 \\
\hline 07 & 1,33 & 1,33 & 1,33 \\
\hline 08 & 1,33 & 0,00 & 0,00 \\
\hline 09 & 0,00 & 1,33 & 2,67 \\
\hline 10 & 0,00 & 4,00 & 0,00 \\
\hline 11 & 2,67 & 1,33 & 2,67 \\
\hline 12 & 3,75 & 1,25 & 0,00 \\
\hline 13 & 1,25 & 1,25 & 0,00 \\
\hline 14 & 0,00 & 1,25 & 0,00 \\
\hline 15 & 1,25 & 0,00 & 0,00 \\
\hline 16 & 0,00 & 1,43 & 0,00 \\
\hline 17 & 0,00 & 1,43 & 1,43 \\
\hline 18 & 0,00 & 1,43 & 0,00 \\
\hline 19 & 2,00 & 4,00 & 2,00 \\
\hline 20 & 2,86 & 1,43 & 0,00 \\
\hline 21 & 1,66 & 0,00 & 1,66 \\
\hline 22 & 1,33 & 1,33 & 2,67 \\
\hline 23 & 1,43 & 0,00 & 2,86 \\
\hline 24 & 2,86 & 1,43 & 1,43 \\
\hline 25 & 0,00 & 0,00 & 1,43 \\
\hline 26 & 3,33 & 0,00 & 0,00 \\
\hline 27 & 0,00 & 1,66 & 0,00 \\
\hline 28 & 0,00 & 1,66 & 0,00 \\
\hline 29 & 2,22 & 0,00 & 4,44 \\
\hline 30 & 4,44 & 2,22 & 0,00 \\
\hline 31 & 1,33 & 0,00 & 1,33 \\
\hline 32 & 1,33 & 1,33 & 1,33 \\
\hline 33 & 0,00 & 4,00 & 0,00 \\
\hline 34 & 2,66 & 1,33 & 2,66 \\
\hline $\begin{array}{l}\text { Rata-rata } \\
\text { (Average) }\end{array}$ & $1,38 \pm 1,22$ & $1,23 \pm 1,13$ & $1,08 \pm 1,18$ \\
\hline
\end{tabular}


Tabel 3. Laju pancing (book rate) dari rawai dasar berdasarkan ukuran mata pancing di perairan Tukadabu, Timur Bali

Table 3. Hook rate of bottom long line based on book sizes operated in Tukadabu waters, eastern part of Bali

\begin{tabular}{c|c|c|c}
\hline $\begin{array}{c}\text { No. Stasiun } \\
\text { No. Station }\end{array}$ & $\begin{array}{c}\text { Laju pancing / Hook rate } \\
\text { Mata pancing } \\
\text { (Hook) No.5 }\end{array}$ & $\begin{array}{c}\text { Mata pancing } \\
\text { (Hook) No.6 }\end{array}$ & $\begin{array}{c}\text { Mata pancing } \\
\text { (Hook) No.7 }\end{array}$ \\
\hline 35 & 4,25 & 0,00 & 0,00 \\
36 & 0,00 & 11,11 & 0,00 \\
37 & 0,00 & 2,22 & 0,00 \\
38 & 0,00 & 2,50 & 2,50 \\
39 & 2,50 & 5,00 & 0,00 \\
40 & 5,00 & 7,50 & 0,00 \\
41 & 7,50 & 5,00 & 5,00 \\
42 & 0,00 & 5,00 & 5,00 \\
43 & 7,50 & 10,00 & 7,50 \\
44 & 2,50 & 2,50 & 5,00 \\
45 & 2,50 & 2,50 & 0,00 \\
46 & 0,00 & 10,00 & 0,00 \\
\hline Rata-rata & $2,65 \pm 2,74$ & $5,28 \pm 3,47$ & $2,08 \pm 2,6718$ \\
(Average) & & & \\
\hline \hline
\end{tabular}

Apabila jumlah stasiun penangkapan ini digabungkan maka diperoleh ratarata laju tangkap untuk masing-masing ukuran mata pancing No. 5, 6 dan 7 berturut-turut adalah sebesar 1,71; 2,28 dan 1,28. Dari uji statistik ANOVA terlihat bahwa ketiga ukuran mata pancing memberikan laju pancing yang tidak berbeda nyata $(P>0.05)$ (Tabel 4). Namun demikian terdapat kecenderungan bahwa mata pancing ukuran kecil (No. 5 dan 6) mampu menangkap ikan lebih banyak dibanding mata pancing yang lebih besar (No. 7). Penelitian serupa juga pernah dilakukan Ralston (1982) di perairan Pasifik dengan menggunakan 4 jenis ukuran mata pancing untuk menangkap kakap laut dalam (opakapaka, Pristipomoides filamentosus).

Ternyata hasil tangkapan yang diperoleh tidak berbeda nyata, tetapi terdapat kecenderungan bahwa mata pancing yang berukuran kecil lebih efektif untuk menangkap ikan dibanding mata pancing yang berukuran lebih besar. Hal ini berkaitan dengan kemampuan ikan dalam memakan umpan yang telah dipasang pada mata pancing di mana mata pancing yang berukuran kecil dapat dimakan oleh ikan baik yang berukuran kecil ataupun ikan besar. Menurut Harifin dan Wijopriono (1993) nelayan di perairan Utara Jawa kebanyakan menggunakan mata pancing yang berukuran No. 6 untuk 
menangkap ikan demersal dekat karang seperti kakap dan kerapu. Sedang nelayan di perairan Bali menggunakan pancing ulur untuk menangkap ikan demersal menggunakan ukuran mata pancing lebih kecil.

Tabel 4. Analisis sidik ragam terhadap hasil tangkapan rawai dasar berdasarkan ukuran mata pancing

Table 4. Analysis of variance for bottom long line catch based on book sizes

\begin{tabular}{lcrrrr}
\hline \multicolumn{1}{c}{$\begin{array}{c}\text { Sumber } \\
\text { Source }\end{array}$} & $\mathrm{dK}$ & $\mathrm{JK}$ & RJK & F-hit & $\mathrm{F}(0,05)$ \\
\hline $\begin{array}{l}\text { Rata-rata (Means) } \\
\text { Antar kelompok } \\
\text { (Among group) }\end{array}$ & 1 & 426,98 & 426,98 & & \\
$\begin{array}{l}\text { Dalam kelompok } \\
\text { (Witbin group) }\end{array}$ & 135 & 629,34 & 11,67 & 2,50 ns & 3,92 \\
\hline Total & 138 & $1.079,94$ & 443,31 & & \\
\hline \hline
\end{tabular}

ns: $p>0,05$

Jenis-jenis ikan yang tertangkap rawai dasar selama percobaan penangkapan di perairan Jemeluk dan Tukadabu adalah ikan kakap (Lutjanus spp.), lencam (Letbrinus lentjam), kerapu (Epinephelus spp.), kue (Caranx spp.), pari (Dasyatis spp.), cucut (Charcharinus spp.), remang (Congresox spp.), buntal (Diodon spp.), botana (Acanthurus spp.) dan barakuda (Sphyraena spp.) (Tabel 5). Semua jenis ikan yang tertangkap adalah ikan demersal, kecuali barakuda satu jenis ikan pelagis. Tertangkapnya barakuda kemungkinan bersamaan dengan saat penarikan tali pancing, hal ini terbukti bahwa ikan barakuda yang tertangkap masih dalam keadaan hidup. Jenis ikan yang tertangkap dalam uji coba ini hampir sama dengan hasil pengamatan rawai dasar yang dilakukan Nasution et al. (1994) di perairan Utara Jawa di mana hasil tangkapan dominan adalah remang, kakap, dan cucut.

Dari Tabel 5 juga terlihat bahwa secara individu jenis ikan kakap banyak tertangkap pada mata pancing No. 5 (14 ekor) dan No. 6 (10 ekor). Demikian juga dengan ikan kerapu dan kue yang merupakan jenis ikan ekonomis penting lainnya banyak tertangkap pada mata pancing No. 5 dan 6. Sedang jenis ikan pari banyak tertangkap dengan mata pancing No. 7 yaitu sebanyak 10 ekor.

Dari hasil pengukuran panjang beberapa jenis ikan tidak terlihat adanya pengaruh ukuran mata pancing terhadap besar ikan yang tertangkap (Tabel 6). Namun khusus ikan kakap terdapat kecenderungan semakin besar ukuran mata pancing dapat menangkap ikan semakin besar ukurannya. Ralston (1982) juga menyatakan bahwa ukuran ikan kakap laut dalam dan kerapu yang tertangkap 
dengan pancing cenderung mengikuti ukuran mata pancing yang digunakan meskipun secara statistik tidak berbeda nyata.

Tabel 5. Komposisi hasil tangkapan rawai dasar berdasarkan ukuran mata pancing selama percobaan penangkapan

Table 5. Catch composition for bottom longline based on book sizes during experimental fishing

\begin{tabular}{|c|c|c|c|c|c|c|}
\hline \multirow[t]{2}{*}{$\begin{array}{l}\text { Jenis ikan } \\
\text { Species }\end{array}$} & \multicolumn{2}{|c|}{$\begin{array}{l}\text { Mata pancing } \\
(\text { Hook) No.5 }\end{array}$} & \multicolumn{2}{|c|}{$\begin{array}{l}\text { Mata pancing } \\
(\text { Hook }) \text { No.6 }\end{array}$} & \multicolumn{2}{|c|}{$\begin{array}{l}\text { Mata pancing } \\
(\text { Hook }) \text { No. } 7\end{array}$} \\
\hline & Ekor (Ind.) & Kg & Ekor (Ind) & $\mathrm{K}_{\mathbf{g}}$ & Ekor (Ind) & $\mathbf{K}_{\mathbf{g}}$ \\
\hline $\begin{array}{l}\text { Kakap } \\
\text { (Lutjanus spp.) }\end{array}$ & 14 & 15,50 & 10 & 8,21 & 6 & 10,47 \\
\hline $\begin{array}{l}\text { Lencam } \\
\text { (Letbrinus lentjam) }\end{array}$ & 1 & 1,00 & 2 & 2,50 & 1 & 1,10 \\
\hline $\begin{array}{l}\text { Kerapu } \\
\text { (Epinephelus spp.) }\end{array}$ & 5 & 11,56 & 7 & 18,45 & 3 & 7,25 \\
\hline $\begin{array}{l}\text { Kue } \\
\text { (Caranx spp.) }\end{array}$ & 4 & 16,63 & 7 & 19,80 & 2 & 6,10 \\
\hline $\begin{array}{l}\text { Pari } \\
\text { (Dasyatis spp.) }\end{array}$ & 7 & 22,40 & 7 & 38,25 & 10 & 58,32 \\
\hline $\begin{array}{l}\text { Cucut } \\
\text { (Charcharinus spp.) }\end{array}$ & 5 & 9,35 & 9 & 50,55 & 4 & 22,89 \\
\hline $\begin{array}{l}\text { Remang } \\
\text { (Congresox spp.) }\end{array}$ & 4 & 1,85 & 12 & 5,25 & 4 & 2,19 \\
\hline $\begin{array}{l}\text { Buntal } \\
\text { (Diodon spp.) }\end{array}$ & 4 & 10,11 & 1 & 1,19 & 2 & 5,35 \\
\hline $\begin{array}{l}\text { Botana } \\
\text { (Acantburus spp.) }\end{array}$ & 0 & 0,00 & 0 & 0,00 & 1 & 2,17 \\
\hline $\begin{array}{l}\text { Barakuda } \\
\text { (Spbyraena spp.) }\end{array}$ & 1 & 3,05 & 0 & 0,00 & 0 & 0,00 \\
\hline
\end{tabular}


Tabel 6. Kisaran ukuran panjang total beberapa jenis ikan yang dominan tertangkap dengan rawai dasar berdasarkan ukuran mata pancing

Table 6. Range of total length for some species of fish caught dominantly by bottom longline based on hook sizes

\begin{tabular}{lccc}
\hline \hline \multirow{4}{*}{$\begin{array}{l}\text { Jenis ikan } \\
\text { Species }\end{array}$} & \multicolumn{3}{c}{ Panjang total / Total lengtb (cm) } \\
\cline { 2 - 4 } & $\begin{array}{c}\text { Mata pancing } \\
\text { (Hook) No.5 }\end{array}$ & $\begin{array}{c}\text { Mata pancing } \\
\text { (Hook) No.6 }\end{array}$ & $\begin{array}{c}\text { Mata pancing } \\
\text { (Hook) No.7 }\end{array}$ \\
\hline Kakap & $15,0-62,5$ & $15,0-52,5$ & $25,0-72,0$ \\
(Lutjanus spp.) & $(32,30)$ & $(34,17)$ & $(40,50)$ \\
Kerapu & $31,5-45,0$ & $31,0-47,5$ & $25,0-76,5$ \\
(Epinephelus spp.) & $(46,90)$ & $(55,50)$ & $(42,83)$ \\
Kue & $30,0-72,0$ & $54,0-75,0$ & $33,0-55,0$ \\
(Caranx sp.) & $(58,75)$ & $(61,00)$ & $(44,00)$ \\
Remang & $65,0-66,0$ & $50,0-57,0$ & $66,0-72,0$ \\
(Congresox spp.) & $(65,0)$ & $(55,50)$ & $(68,00)$ \\
Cucut & $45,0-50,0$ & $65,0-122,0$ & $69,0-75,0$ \\
(Charcarinus spp.) & $(47,50)$ & $(93,50)$ & $(72,50)$ \\
\hline \hline
\end{tabular}

Keterangan (Note): (...) adalab rata-rata panjang total (means of total length)

\section{KESIMPULAN DAN SARAN}

(1) Ukuran mata pancing No. 5, 6 dan 7 pada pengoperasian rawai dasar memberikan laju tangkap yang tidak berbeda nyata, walaupun ada kecenderungan mata pancing No. 5 dan 6 memperoleh hasil tangkapan lebih tinggi dibandingkan dengan mata pancing No. 7 .

(2) Rawai dasar yang dioperasikan di perairan Tukadabu dengan kedalaman lebih dari $50 \mathrm{~m}$ rata-rata laju pancingnya lebih tinggi dibandingkan dengan rawai dasar yang dioperasikan di perairan Jemeluk yang relatif lebih dangkal antara 20-50 m.

(3) Jenis ikan ekonomis penting yang banyak tertangkap oleh rawai dasar antara lain adalah kakap, kerapu, dan kue.

(4) Ukuran ikan yang tertangkap oleh rawai dasar yang menggunakan mata pancing No. 5, 6 dan 7 ternyata tidak berbeda nyata.

\section{DAFTAR PUSTAKA}

Direktorat Jenderal Perikanan, 1993. Statistik Perikanan Indonesia Tahun 1991.

Direktorat Jenderal Perikanan. Deptan. Jakarta. 
Harifin, H. dan Wijopriono, 1993. Pengamatan Terhadap Beberapa Aspek Operasional Rawai Dasar di Juana, Jawa Tengah. Jur. Pen. Perik. Laut. No.81:29-39.

Koike, A and S. Takeuchi, 1970. Selection Curve of The Hook of Pole Fishing. Jour. Tokyo. Univ. Fisheries, Vol.57 (1):1-7.

Longhurst, A. R. and D. Pauly, 1987. Ecology of Tropical Ocean. Academic Press Inc. San Diego, California. USA. p:145-183.

Nasution, C, Sawon dan Sudjianto, 1994. Penelitian Penggunaan Alat Penarik Tali (Line Hauler) Pada Rawai Dasar (Bottom Long Line) di Juwana, Oktober-Nopember 1994. Interim Report. (Tidak Diterbitkan).

Ralston, S., 1982. Influence of Hook Size in the Hawaiian Deep-sea Handline Fishery. Can. Jour. Fish. Aquat. Sci. Vol.39:1297-1302.

Sudjana. 1984. Metoda Statistika. Edisi-3. Tarsito. Bandung. 484 p. 